\title{
Coupled Heat And Moisture Transfer Simulations On Building Components Retrofitted With A Newly Developed Aerogel-based Coating
}

\author{
Stefano Fantucci ${ }^{1}$, Elisa Fenoglio ${ }^{1}$, Valentina Serra ${ }^{1}$, Marco Perino ${ }^{1}$ \\ ${ }^{1}$ TEBE research group, Department of Energy, Politecnico di Torino, Torino, Italy
}

\begin{abstract}
The study investigates the effectiveness of an energy retrofit strategy based on the adoption of an aerogelbased coating aimed at mitigating thermal bridges and reducing energy losses. The material was developed and characterised in the framework of the Horizon-2020 project 'Wall-ACE'. The analyses were aimed to validate coupled heat and moisture transfer simulation models at the component level through the comparison with in-field experiments. Furthermore, the results achieved by the heat and moisture simulations were compared with those obtained by means of standardised simplified methods to verify if the adoption of more accurate calculation procedures gives different results.
\end{abstract}

\section{Introduction}

The high energy losses and huge energy demand related to buildings are aspects widely known. Weak elements of the opaque envelope are thermal bridges, and it was estimated that their impact on the heating energy needs in different EU countries is generally up to $30 \%$ (Citterio et al. 2008).

Reduction of the buildings energy demand and the improvement of their energy efficiency is necessary and required (i.e. an improvement of $27 \%$ by 2030 is required in the EU). In addition, poorly insulated envelopes can be affected by several issues like surface condensation risk, that can contribute to the development of biological growth with a relevant impact on Indoor Environmental Quality. To face these problems and to comply with the heat demand reduction requirements in existing buildings, thermal insulation is the primary solution. In a consistent number of case, insulating from the interior side is the only viable solution, and super insulating materials have to be developed to guarantee proper space saving (Fantucci, Garbaccio et al. 2019).

In the framework of an H2020-project (Wall-ACE), an aerogel-based insulating thermal-coating finishing was developed aimed at reducing energy losses and mitigating thermal bridges. The study here presented aims at analysing the thermal performances of an existing 1920's envelope retrofitted with this newly developed product and verify through coupled heat and moisture transfer simulations the effectiveness of this energy retrofit strategy.

Designers usually verify the suitability of the retrofit choice (i.e. prevention of critical surface humidity and interstitial condensation) through simplified methods based on EN ISO 13788:2012 Standard (Glaser method). Nevertheless, this methodology may be not fully adequate to represent the complexity of the physical phenomena occurring in the building components due to a series of assumptions:

- the boundary conditions are assumed to be constant;

- the initial moisture in the construction is assumed to be completely evaporated;

- heat and moisture flow are considered monodimensional;

- the latent heat exchange phenomena are neglected;

- the material properties variation as a function of moisture content is neglected;

- the moisture uptake and liquid water transport in materials are neglected;

- 2D heat and moisture transfer phenomena are neglected.

As highlighted by Cascione et al. 2017 and by Mumovic et al. 2007, the adoption of more accurate Heat and Moisture Transfer (HMT) simulation instead of Glaser based methods may lead to different results. Most of the studies confirmed that the application of the simplified steady-state method often determines an overestimation of the condensation risk and at the same time that some critical aspects result underestimated. So the results of simplified analyses can affect the designers retrofit choice by discharging solutions that can be potentially suitable if verified with dynamic coupled heat and moisture simulations and, vice versa, to promote not working solutions.

The aim of the paper is thus to investigate the robustness of using 2D dynamic coupled heat and moisture transfer simulations (EN 15026 Standard) by the comparison with a monitored case study. Moreover, the simulation results were compared with the ones obtained by using simplified steady-state methods (ISO 13788). The model was finally adopted to simulate the retrofitted wall in different scenarios with different aerogel-based coating finishing thickness in order to:

- assess the reduction of the linear thermal transmittance of the thermal bridges determined in both steady-state thermal and in dynamic hygrothermal simulations;

- analyse the surface temperature in critical points highlighting the frequency of condensation risk phenomena. 


\section{The case study}

The case study selected for the application of the aerogel coating is an existing 1920s building (Figure 1a) located in Turin (Italy, Lat. $45^{\circ} \mathrm{N}$, Long. $7.65^{\circ} \mathrm{E}$ ). Two external walls with the same orientation (south-east) were chosen as reference wall (RW) and coated wall (CW) respectively. On the latter, a $\sim 12 \mathrm{~mm}$ thick internal aerogel-based coating layer was internally applied (Figure 1b).
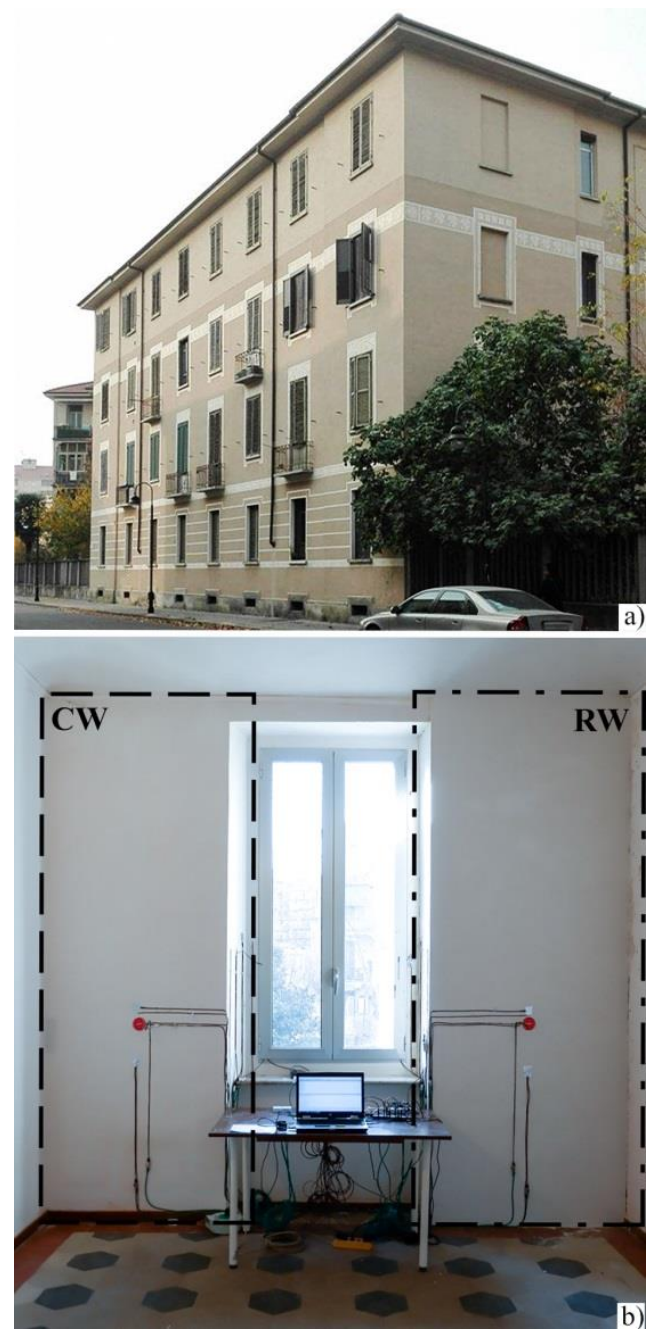

Figure 1: a) the demonstration building; b) the two monitored wall configurations;

\section{Methods}

\section{Experimental monitoring campaign}

To have a detailed overview of the wall thermal behaviour and to validate the simulation model, a monitoring campaign was carried out on both the walls (RW and CW) for the period 21 December 2017 - 7 March 2018

A series of control points were selected on both the walls; 16 T-type thermocouples and 2 heat flux meter sensors Hukseflux HFP01 (measurement uncertainty $\pm 5 \%$ ) were placed on the two walls as shown in Figure 2c. In addition, a Hukseflux LP02 (second-class pyranometer sensor) was adopted to measure the incident solar radiation), while the indoor and outdoor relative humidity were monitored by means of Testo $175-\mathrm{H} 2$ datalogger (measurement uncertainty $\pm 3 \%$ ). The T-type thermocouples adopted were preliminarily calibrated by means of thermostatic bath and a calibrated PT100; in this way, the uncertainty of the sensors and of the data-logging system results lower than $\pm 0.25^{\circ} \mathrm{C}$. The sensors (thermocouples, heat flux meters and pyranometers) were connected to a data-logger (dataTaker DT85) to record the data that were collected with a time step of 15 minutes.

To reduce the measurement uncertainty, the room was heated at $23 \pm 0.5^{\circ} \mathrm{C}$ by a radiator located in the opposite side of the monitored wall, in this way, a high temperature difference between the indoor and outdoor side $\left(>10^{\circ} \mathrm{C}\right)$ was guaranteed for most of the monitoring period.

It is worth to be mentioned that an initial survey was carried out to be sure that the two analysed components (CW and RW) were identical. A difference $<1 \%$ in the $\mathrm{CW}$ and RW thermal transmittance were measured before the application of the aerogel-based coating.

Considering that in the scope of this paper, the in-field monitoring results are functional to the validation of the simulations, the experimental results are not extensively reported. However, a more deepen analysis of the monitoring campaign can be found in previous studies of the Authors (Fantucci et al. 2018, Fantucci, Fenoglio et al. 2019).
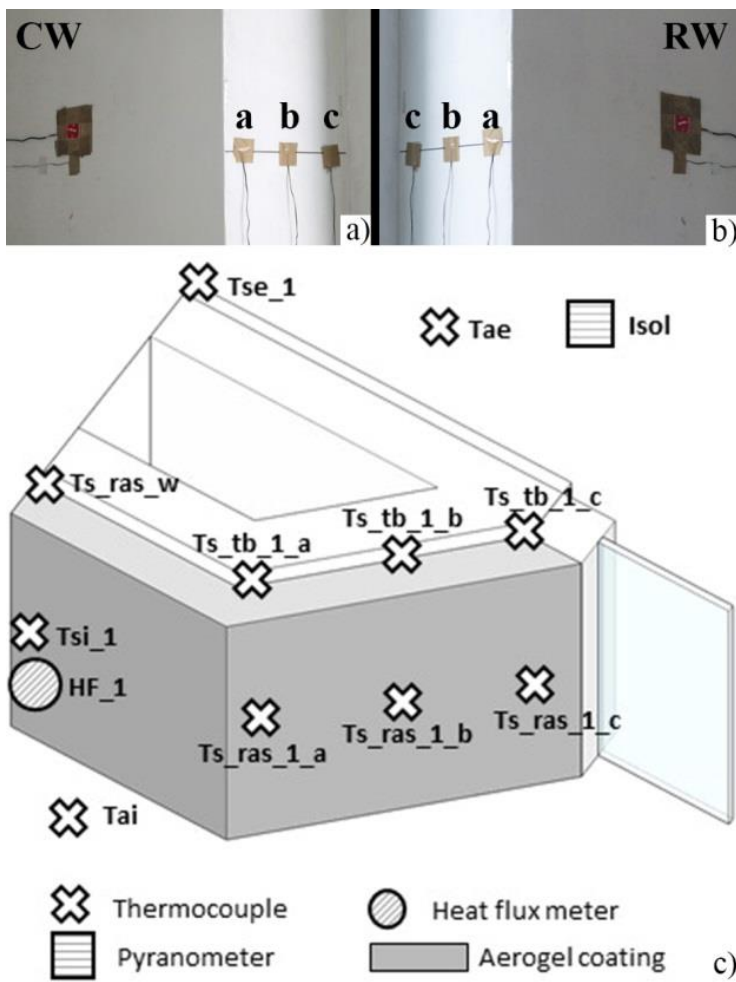

c)

Figure 2: $a-b$ ) detail of the sensors applied on the centre of walls and thermal bridges; c) a schematic view of the coated wall reporting the monitoring sensors. 


\section{Simulations analysis}

The dynamic simulations were performed by means of Delphin 5.9 that allows simulating the coupled heat and moisture transport in porous materials; the software can be used for various applications including the thermal bridges simulations, the condensation risk and the moisture storage in the building structures.

The simulations were performed on different wall configurations (Figure 3) that are:

- A0: the wall without any thermal insulating coating, adopted as a reference (monitored wall);

- A1_3: the wall with a $3 \mathrm{~mm}$ thick aerogel-based coating application;

- A1_12: the wall with a $12 \mathrm{~mm}$ thick aerogel-based coating application (monitored wall).

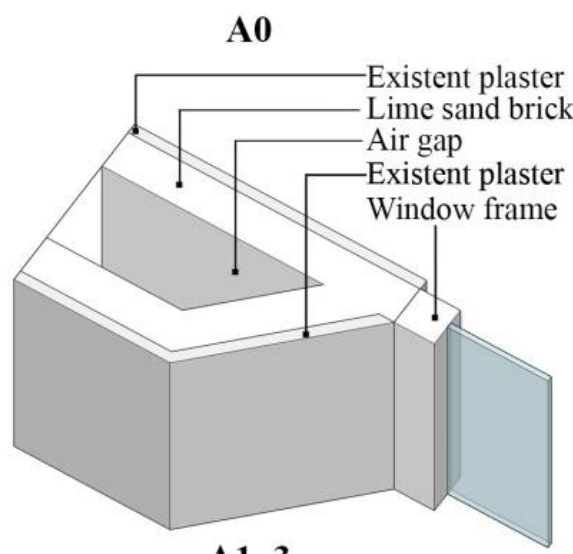

A1_3

Aerogel-based coating $3 \mathrm{~mm}$ thickness

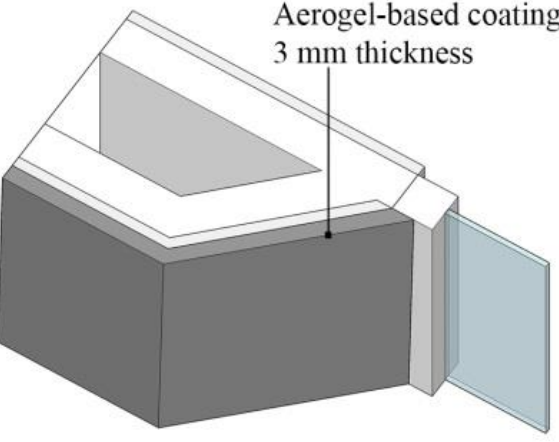

A1 12

Aerogel-based coating $12 \mathrm{~mm}$ thickness

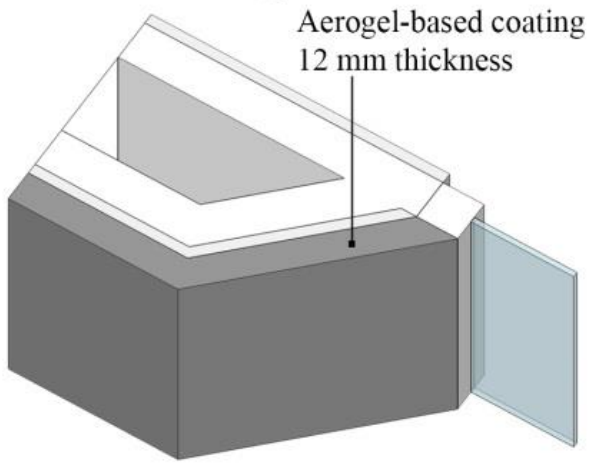

Figure 3: The walls configurations simulated

\section{Model creation and validation}

A preliminary validation was performed to verify the agreement between the simulated results and the monitored ones, like the process described and pursued by Galliano et al. 2016. To create the model for the wall simulations, the different elements that composed the node between the wall and window were measured and subsequently modelled in Delphin 5.9. Nevertheless, to minimize the computational cost, some simplifications and assumptions were needed:

- all the geometries have been modelled as orthogonal;

- the window frame, as well as the glazing unit, were modelled as homogeneous elements considering an equivalent thermal conductivity;

- the thickness of the coating was considered constant along the entire wall $(\sim 12 \mathrm{~mm})$

- no mortar joints were modelled between the bricks.

The materials properties (Table 1) were taken from the Delphin database (IBK TU Dresden), selecting the materials in accordance with those found during the survey phase. An equivalent thermal conductivity was assumed for the aluminium frame of the window as well as the thermal resistance of the air gap was determined according to the ISO 6946:2017 Standard.

A different approach was used for the aerogel-based thermal insulating coating layer. The material hygrothermal properties were the one assessed through laboratory test (dry bulk density $\rho$, water vapour diffusion resistance factor $\mu$, specific heat $c_{p}$, thermal conductivity $\lambda$ as a function of water content and moisture retention curve).

Table 1:Summary of the material properties adopted for the walls simulations

\begin{tabular}{|c|c|c|c|c|c|}
\hline Layer & $\boldsymbol{s}$ & $\boldsymbol{\rho}$ & $\lambda_{\text {dry }}$ & $\boldsymbol{c}_{\mathbf{p}}$ & $\boldsymbol{\mu}$ \\
\hline & {$[\mathrm{mm}]$} & {$\left[\mathrm{kg} / \mathrm{m}^{3}\right]$} & {$[\mathrm{W} / \mathrm{mK}]$} & {$[\mathrm{J} / \mathrm{kgK}]$} & {$[-]$} \\
\hline $\begin{array}{c}\text { Existing } \\
\text { Plaster }\end{array}$ & 10 & 1800 & 0.820 & 800 & 12.0 \\
\hline $\begin{array}{c}\text { Lime } \\
\text { Sand } \\
\text { Brick }\end{array}$ & 125 & 1705 & 1.188 & 890 & 18.7 \\
\hline Air Gap & 250 & 1 & 1.380 & 1050 & 0.2 \\
\hline $\begin{array}{c}\text { Lime } \\
\text { Sand } \\
\text { Brick }\end{array}$ & 125 & 1705 & 1.188 & 890 & 18.7 \\
\hline $\begin{array}{c}\text { Existing } \\
\text { Plaster }\end{array}$ & 10 & 1800 & 0.820 & 800 & 12.0 \\
\hline $\begin{array}{c}\text { Aerogel- } \\
\text { based }\end{array}$ & 12 & 336 & 0.051 & 1091 & 7.5 \\
Coating & & & & & \\
\hline
\end{tabular}

Finally, the time discretisation was settled to $15 \mathrm{~min}$ (monitoring frequency), while the space discretisation of the model was defined through the automatically subdivision option and subsequently the grid was refined near to the point on which the sensors were applied during the monitoring phase.

After the definition of the geometry and the material properties definition, the validation was performed 
through the comparison between data collected during the monitoring campaign and the results of the numerical model. The simulations to be used for validation purposes were performed by using the same boundary conditions collected during the measurement campaign (internal and external temperature, internal and external relative humidity, incident solar radiation) and the same time step used for the data acquisition (15 minutes). The results were taken in each control point according to Figure 2 and compared with the monitored data of the coldest week (26 February 2018 - 3 March 2018).

The results (simulated vs measured) were plotted as dispersion surrounding the line $\mathrm{y}=\mathrm{x}$ highlighting the values that fall within the $95 \%$ of the data (Figure 4 dotted line). Moreover, the Root Mean Square Error (eq.1) was calculated for each control point Table 2 (Table 2).

$$
R M S E=\sqrt{n^{-1} \cdot \sum_{j=1}^{n}\left(s_{j}-m_{j}\right)^{2}}
$$

where $s_{\mathrm{j}}$ and $m_{\mathrm{j}}$ are the simulated values and the measured values for times $j$, and $n$ is the number of values of the series, respectively.

It can be observed that the RMSE of the temperatures were less than $0.5{ }^{\circ} \mathrm{C}$ except for the external surface temperature; this can be due to the number of simultaneous physical phenomena affecting the external surface temperatures (i.e. the shortwave solar radiation, the effect of wind, the long-wave counter-radiation). The higher RMSE value was observed for the heat flux density (HF_1), but with a percentage error below 5\%, which is the expected accuracy of the sensor.

The slight discrepancy between monitored and simulated values are due to different sources of inaccuracies that can be divided in:

- modelling assumptions and simplifications;

- measurements uncertainty, in both, the monitoring sensors and in the determination of the material properties (e.g. thermal conductivity, density, specific heat).

Table 2: RMSE value for each control point

\begin{tabular}{|c|c|c|}
\hline Control point & RMSE & Unit \\
\hline Ts_ras_w & 0.28 & {$\left[{ }^{\circ} \mathrm{C}\right]$} \\
\hline Tse_1 & 0.70 & {$\left[{ }^{\circ} \mathrm{C}\right]$} \\
\hline Ts_coat_1_a & 0.27 & {$\left[{ }^{\circ} \mathrm{C}\right]$} \\
\hline Ts_coat_1_b & 0.56 & {$\left[{ }^{\circ} \mathrm{C}\right]$} \\
\hline Ts_coat_1_c & 0.59 & {$\left[{ }^{\circ} \mathrm{C}\right]$} \\
\hline Ts_tb_1_a & 0.47 & {$\left[{ }^{\circ} \mathrm{C}\right]$} \\
\hline Ts_tb_1_b & 0.28 & {$\left[{ }^{\circ} \mathrm{C}\right]$} \\
\hline Ts_tb_1_c & 0.25 & {$\left[{ }^{\circ} \mathrm{C}\right]$} \\
\hline Tsi_1 & 0.27 & {$\left[{ }^{\circ} \mathrm{C}\right]$} \\
\hline HF_1 & 0.79 & {$\left[\mathrm{~W} / \mathrm{m}^{2}\right]$} \\
\hline
\end{tabular}

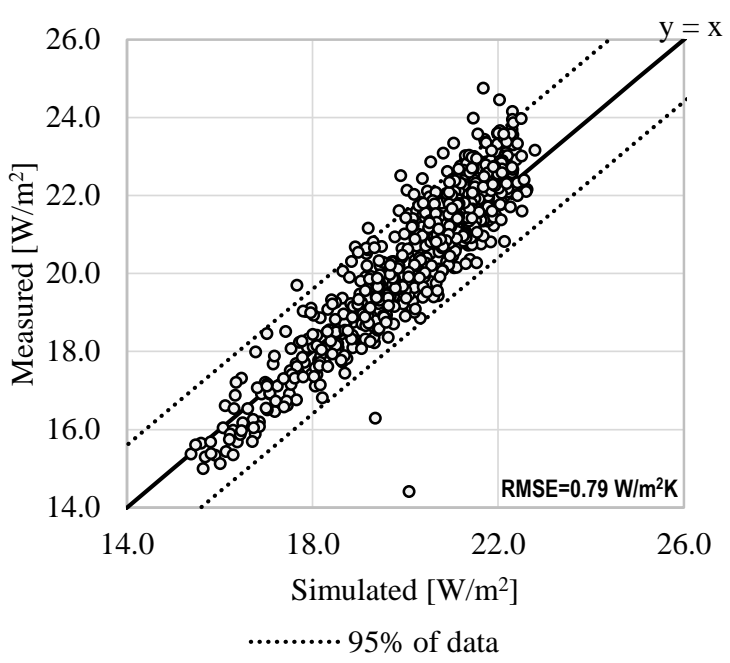

a)

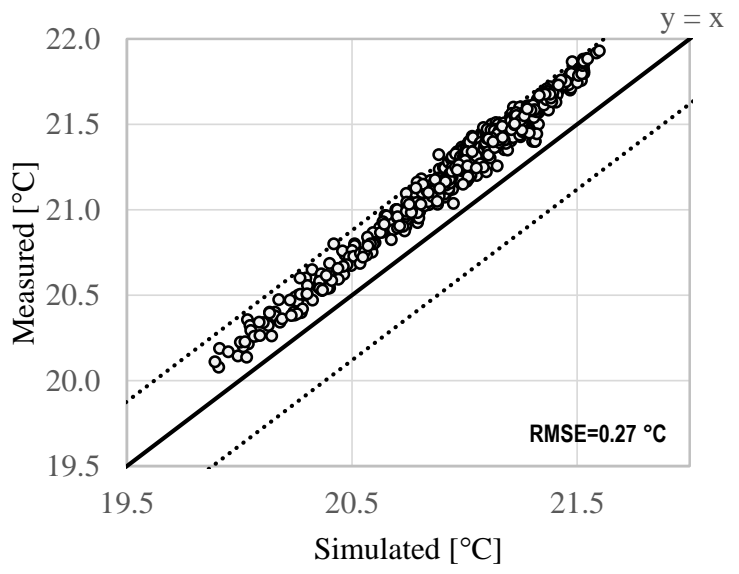

b)

Figure 4: Data simulated vs measured of a) heat flux and $b$ ) internal surface temperature,

\section{Determination of the $\psi$-value}

As known a high percentage of heat losses can be related to thermal bridges [Mao et al. 1997, Citterio et al. 2008, and Theodosiou et al. 2008], thus an accurate determination of their value is necessary to correctly assess the heating energy demands of buildings.

Since Delphin allows to perform 2D simulation, in the analysis, it was possible to assess both the 1D centre of wall heat flux density $\varphi_{1 d} / A$ and the $2 \mathrm{D}$ total heat flux $\varphi_{2 d}$ including thermal bridges. The linear thermal transmittance $(\psi)$ of the thermal bridge between wall and window frame was calculated, and in order to verify how the thermal coating could reduce the $\psi$-value, the simulations were performed with the three-different wall configurations described in Figure 3.

In order to establish if a variation on the boundary conditions could affect the $\psi$-value, different simulations were performed:

- $\quad$ steady-state $2 \mathrm{D}$ heat transfer simulation $(\psi)$

$\psi=\frac{\varphi_{2 \mathrm{D}}-\varphi_{1 \mathrm{D}}}{l \cdot \Delta T}[\mathrm{~W} / \mathrm{mK}]$ 
where:

$l$ is the length of the component (set as $1 \mathrm{~m}$ ), and

$\Delta T$ is the temperature difference between the internal and external side $\left[{ }^{\circ} \mathrm{C}\right]$;

- dynamic hygrothermal simulations $\left(\psi^{*}\right)$;

The $\psi^{*}$ was calculated according to eq. (3)

$\psi^{*}=\frac{E_{2 \mathrm{D}}-E_{1 \mathrm{D}}}{n \cdot l \cdot \Delta T}[\mathrm{~W} / \mathrm{mK}]$

where:

$n$ : number of hours in which heat losses occur during the heating season [-];

- $\quad E_{2 \mathrm{D}}$ : total energy loss including the thermal bridge [Wh];

- $\quad E_{1 \mathrm{D}}$ : energy loss by one-dimensional heat flux [Wh];

- $E$ represents the integer of the heat losses in the heating season, as shown in eq. (4)

$E=\int_{i=1}^{n} \varphi_{i}[W h]$

where: $\varphi_{i}$ is the heat flux through the opaque envelope [W];

\section{Condensation risk}

The ISO 13788 standard allows calculating the surface and the interstitial condensation risk. In this study, the results obtained through the simplified calculation methods and those obtained performing the dynamic hygrothermal simulation were compared.

Concerning the surface condensation risk, it can be determined by comparing the $f_{\mathrm{Rsi}}$ (temperature factor on the internal surface) with the $f_{\text {Rsi,min }}$ (design temperature factor on the internal surface) which represents the minimum factor to avoid the surface condensation and mould growth risk.

The surface condensation risk can be calculated for each configuration starting from:

- the monthly average data of internal temperature and relative humidity that, in this case, were derived from ASHRAE 160 (maximum relative humidity of 70\%);

- the monthly average external temperature and relative humidity.

The internal saturation pressure was calculated from eq. (5):

$p_{\text {sat }}(\bar{\theta})=610.5 \mathrm{e}^{\frac{17.269 \cdot T}{237.3+T}} \quad$ if $T \geq 0^{\circ} \mathrm{C}$;

From these values calculated for each month, the internal pressure was determined, and then the minimum saturation pressure was calculated; the results allowed to calculate the minimum surface temperature acceptable to avoid condensation and mould growth risk. The $f_{\text {Rsi,min }}$ (6) was thus determined for each month:

$f_{\mathrm{Rsi}, \min }=\frac{T_{s i, \min }-T_{e}}{T_{i}-T_{e}}$

$f_{\mathrm{Rsi}}=\frac{T_{s i}-T_{e}}{T_{i}-T_{e}}$

The maximum value was selected as the reference one $\left(f_{\text {Rsi,max }}\right)$ and compared with the monthly $f_{\text {Rsi }}$ value calculated for every wall configuration analysed in order to verify if:

$f_{\mathrm{Rsi}} \geq f_{\mathrm{Rsi} \text { max }}$ when this condition is satisfied the condensation and mould growth risk on the surface can be considered avoided.

For the different walls configurations, the calculation was performed using:

- the internal and external mean temperature and relative humidity for each month derived from climatic data used in the dynamic simulation;

- the internal surface temperature obtained from the last heating period of simulations (4 years were simulated to reach the equilibrium moisture content in the wall layers).

\section{Results and discussions \\ $\Psi$-value}

In Figure 5 the $\psi$ (linear thermal transmittance calculated by means of steady-state $2 \mathrm{D}$ simulations) and $\psi^{*}$ (linear thermal transmittance calculated by means of dynamic hygrothermal simulations) values for the reference (A0) and the retrofitted wall respectively with 3 and $12 \mathrm{~mm}$ of the insulating coat (A1_3, A1_12) are reported.

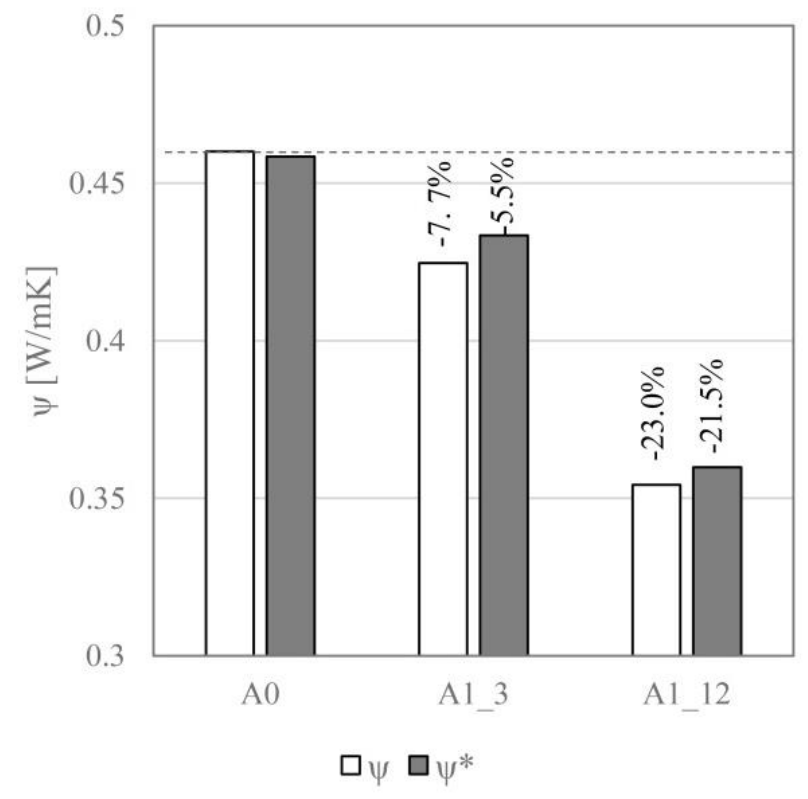

Figure 5: $\psi$ and $\psi^{*}$ values calculated through simulations and the percentage difference between dynamic hygrothermal and steady state.

As expected, it is possible to observe a reduction of the $\psi$ value when the coating is applied, and the higher the coating thickness, the lower the linear thermal transmittance. The maximum reduction of $\psi(21.5-23 \%)$ is obtained with $12 \mathrm{~mm}$ of aerogel-based coating finishing. While for the A1_3 configuration, a slight reduction between $5.5 \%$ and $7.7 \%$ can be highlighted.

Furthermore, no significant difference between the $\psi$ and $\psi^{*}$ was observed, so it can be asserted that for the analysed case study both steady state or dynamic hygrothermal analyses can be performed to assess the linear thermal transmittance. 


\section{Surface condensation risk}

To evaluate the condensation risk and the effect of the coating application, an analysis of the surface temperature for the different wall configurations was performed. Two points were analysed (Figure 6):

- (a) a point near the thermal bridge (critical point);

- (b) a point in the centre of the wall.

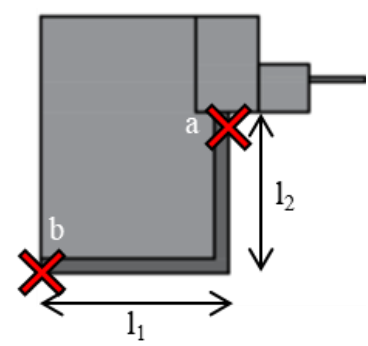

Figure 6: Point for surface condensation risk analysis

The $f_{\mathrm{Rsi}}$ value reached in point $b$ by each wall configuration is reported in Table 3 and compared with the limit value to avoid condensation. Adopting the simplified EN 13788 method for any configurations, also for the retrofitted ones, the $f_{\mathrm{Rsi}}$, IsO13788 value is always lower than $f_{\text {Rsimax }}$ which means that the designed solutions do not comply with the requirements of the standard. Performing the dynamic hygrothermal simulation (according to EN15026 method) a completely different result was obtained, $f_{\mathrm{Rsi}}$ HMT sim. is always higher than $f_{\mathrm{Rs} \text {, max }}$ meaning that no condensation and mould growth risk occurs.

Table 3: $f_{\text {Rsi,max }}$ and $f_{\text {Rsi }}$ values for each wall configurations (the worst value is reported).

\begin{tabular}{|l|l|l|l|}
\hline & $\mathrm{f}_{R s i, \max }$ & $\mathrm{f}_{R s i, \text { ISO } 13788}$ & $\mathrm{f}_{R s i \text {, HMT sim. }}$ \\
\hline \multirow{2}{*}{ A0 } & \multirow{3}{*}{0.83} & 0.65 & 0.84 \\
\cline { 1 - 1 } A1_3 & 0.67 & 0.85 \\
\cline { 1 - 1 } A1_12 & & 0.73 & 0.88 \\
\hline
\end{tabular}

In Figure 7, the cumulative frequency distribution of the winter surface temperature obtained from the 2D dynamic hygrothermal simulations is presented. Considering the centre of the wall, temperatures are always higher than the dew-point temperature (indoor air temperature $20^{\circ} \mathrm{C}$ and relative humidity $60 \%$ ). Nevertheless, if considering the critical point of the thermal bridge, different results can be highlighted:

- for the A0 configuration the surface condensation risk occurs for $\sim 12 \%$ of the time;

- for the A1_3 configuration the surface condensation risk can occur for less than $3 \%$ of the time;

- for the A1_12 configuration, the surface condensation risk can be considered completely avoided.

Summarising, all the retrofit configurations allow to significantly mitigate or avoid the condensation risk in both the centre of the wall and in the thermal bridge area. Similar results were also highlighted in a previous work of the Authors (Fantucci et al. 2017); the comparison between the surface temperatures of an existing wall and a retrofitted one with a mineral-based thermal coating layer $(6 \mathrm{~mm})$ showed an increment of the surface temperature over the dew point, reducing the condensation risk.

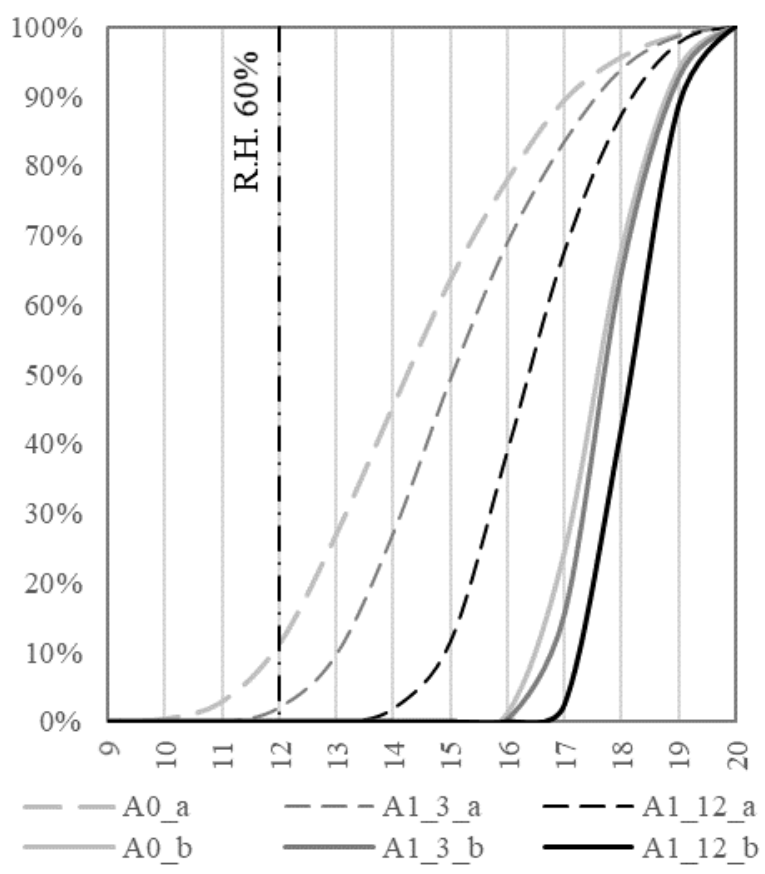

Figure 7:Cumulative frequency of surface temperatures on point $a$ and $b$ compared with the condensation temperature at different $R H$ level (indoor air temperature $20^{\circ} \mathrm{C}$ and relative humidity $60 \%$ )

\section{Interstitial condensation}

The interstitial condensation risk can be evaluated through the Glaser method, according to EN 13788, or with more accurate dynamic hygrothermal simulations.

Adopting the Glaser method results are presented (Figure 8) showing the vapour saturation pressure at the different interfaces compared with the vapour pressure for January (worst month) and for each wall configuration.

From the results, it seems evident that for the proposed retrofit solution interstitial condensation phenomena occur. As reported by the standard, the suitability of the intervention has to be deeply investigated by means of more accurate numerical simulations (i.e. EN 15026). The results of the moisture content in each layer determined through dynamic hygrothermal simulation are reported in Table 4 and compared with the critical moisture content of each material type summarised in EN ISO 13788. It is evident that in each layer, the moisture content is under the critical value. The higher level was reached by the coating layer $\left(\sim 60 \mathrm{~kg} / \mathrm{m}^{3}\right)$ due to the higher relative humidity reached along that side; anyway, the value was below the limit assumed similar to the value reported for the cement-based mortar (180 $\left.\mathrm{kg} / \mathrm{m}^{3}\right)$. 


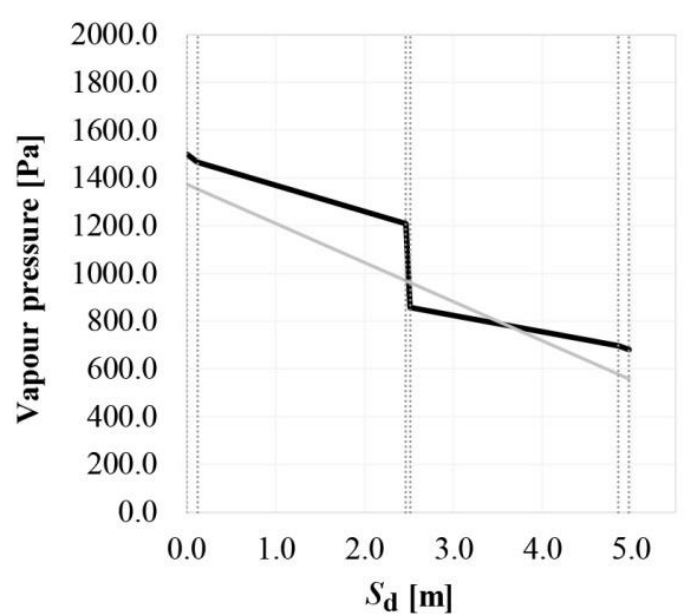

a)
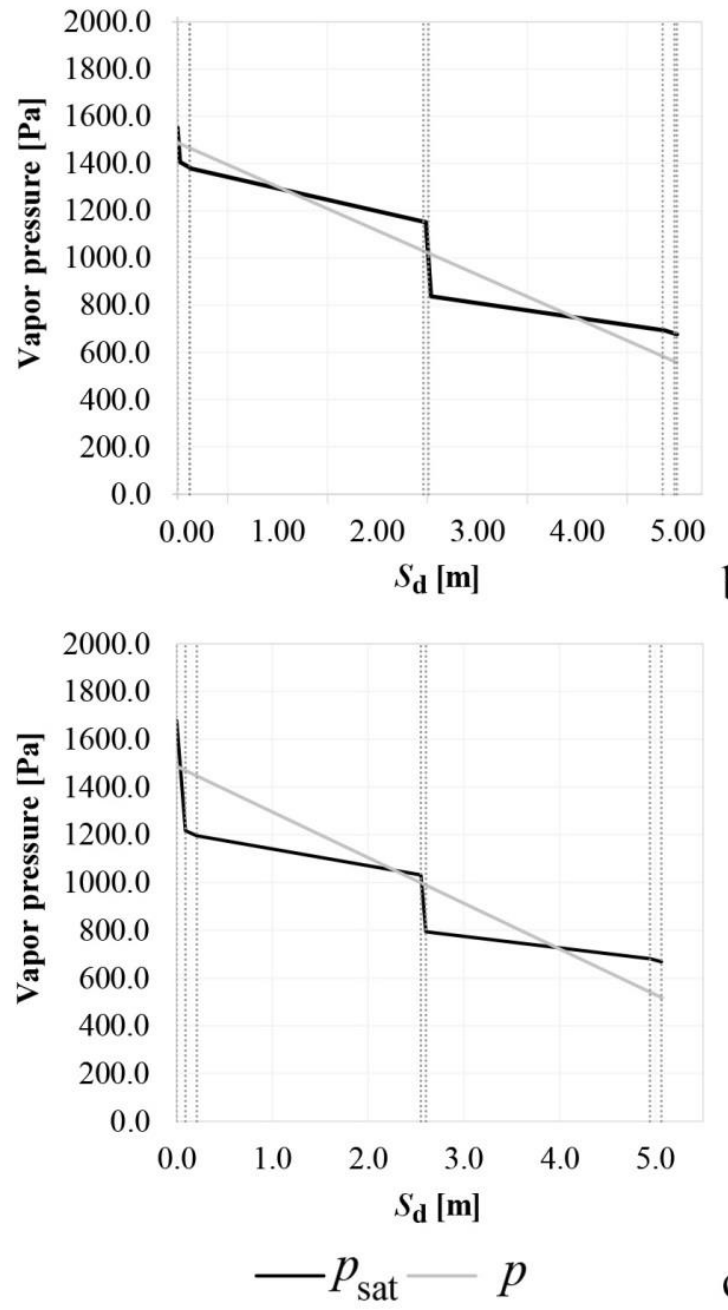

b)

c)

Figure 8: Vapour saturation and vapour pressure for the three different wall configurations $A 0(a), A 1 \_3(b)$, Al_12 (c) for January.
Table 4:Maximum (max) and median (med) moisture content for each material, compared with critical moisture content (EN 13788). Values are in [ $\left.\mathrm{kg} / \mathrm{m}^{3}\right]$

\begin{tabular}{|c|c|c|c|c|c|c|c|}
\hline \multirow[t]{2}{*}{ Layer } & \multicolumn{2}{|c|}{ A0 } & \multicolumn{2}{|c|}{ A1_3 } & \multicolumn{2}{|c|}{ A1_12 } & \multirow[b]{2}{*}{ 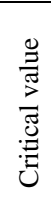 } \\
\hline & 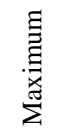 & 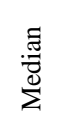 & 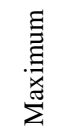 & 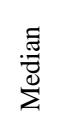 & 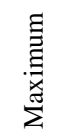 & 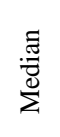 & \\
\hline Coating 11 & - & - & 23.9 & 12.8 & 18.9 & 12.5 & 180 \\
\hline Coating 12 & - & - & 82.5 & 14.6 & 24.3 & 13.2 & 180 \\
\hline $\begin{array}{l}\text { Existent } \\
\text { plaster } 11\end{array}$ & 15.3 & 10.2 & 14.5 & 10.2 & 12.9 & 10.2 & 180 \\
\hline $\begin{array}{l}\text { Existent } \\
\text { plaster } 12\end{array}$ & 25.0 & 8.6 & 15.9 & 8.3 & 11.4 & 8.0 & 180 \\
\hline Masonry & 10.9 & 9.5 & 9.9 & 9.3 & 9.6 & 9.2 & 130 \\
\hline $\begin{array}{l}\text { External } \\
\text { plaster }\end{array}$ & 16.9 & 6.9 & 16.9 & 7.0 & 17.4 & 7.2 & 180 \\
\hline
\end{tabular}

\section{Conclusions}

The hygrothermal behaviour of a retrofit intervention based on an aerogel added coating was analysed, and a comparison of the results obtained adopting different methodologies was performed. The retrofit intervention allows improving the behaviour of the wall and the thermal bridge, as demonstrated by the $2 \mathrm{D}$ dynamic hygrothermal analysis. As the main results, it is possible to highlight that:

- as far as the thermal bridge calculation methods are concerned no differences between the 2D hygrothermal dynamic and the 2D steady state results can be observed;

- with reference to the surface condensation risk, the adoption of the simplified method gives results that are significantly worse than those obtained through the HMT simulations, in which the surface condensation does not occur in any retrofitted wall configuration;

- according to the results of the Glaser method, the risk of interstitial condensation is high. On the contrary, the dynamic HMT simulations show that in each layer, the moisture content was lower than the critical value proposed by the EN ISO 13788 standard.

From the different analysis emerged that, to avoid misleading results and demonstrate the feasibility of the internal retrofit intervention (especially with advanced materials), it is crucial to evaluate the performance by means of 2D dynamic HMT simulations.

\section{Acknowledgement}

The research project Wall-ACE has received funding from the EU Horizon 2020 research and innovation programme under the Grant Agreement No. 723574. The authors wish to thank the project partner ATC and CASE which made available the demonstration building, and Vimark srl which have provided/installed the developed materials in the demonstration site. Further, a special thanks go to Eng. Giulia Grosso, which has supported the research team during the simulation phase. 


\section{References}

Bras A., Gocalves F., Pedro F., Cork-based mortars for thermal bridges correction in a dwelling: Thermal performance and cost evaluation. Energy and Buildings, $72 \quad$ (2014), 296-308. https://doi.org/10.1016/j.enbuild.2013.12.022

Cascione V., Marra E., Zirkelbach D., Liuzzi S., Stefanizzi P. Hygrothermal analysis of technical solutions for insulating the opaque building envelope. Energy Procedia, 126 (2017), 203-210. https://doi.org/10.1016/j.egypro.2017.08.141

Citterio M., Cocco M., Erhorn-Kluttig H. Thermal bridges in the EBPD context overview on MS approaches in regulations. In: ASIEPI information paper; 2008

Delphin. [Online]. Available: http://bauklimatikdresden.de/delphin/index.php

EN 15026:2007. Hygrothermal performance of building components and building elements - Assessment of moisture transfer by numerical simulation.

Fantucci S., Fenoglio E., Grosso G., Serra V., Perino M., Dutto M. and Marino V. Retrofit of the existing buildings using a novel developed aerogel-based coating: results from an in-field monitoring. IBPC2018. International Building Physics Conference. Syracuse, NY. 2018.

Fantucci S., Fenoglio E., Grosso G., Serra V., Perino M., Marino V. and Dutto M. Development of an aerogelbased thermal coating for the energy retrofit and the prevention of condensation risk in existing buildings. Science and Technology for the Built Environment (2019), https://doi.org/10.1080/23744731.2019.1634931

Fantucci S., Garbaccio S., Lorenzati A., Perino M. Thermo-economic analysis of building energy retrofits using VIP - Vacuum Insulation Panels, Energy\&Buildings, 196 (2019), 269-279, doi: https://doi.org/10.1016/j.enbuild.2019.05.019

Fantucci S., Isaia F., Serra V., Dutto M. Insulating coat to prevent mold growth in thermal bridges, Energy Procedia, 134 (2017), 414-422. https://doi.org/10.1016/j.egypro.2017.09.591
Galliano R., Ghazi Wakili K., Stahl T., Binder B., Daniotti B.. Performance evaluation of aerogel-based and perlite-based prototyped insulations for internal thermal retrofitting: HMT model validation by monitoring at demo scale. Energy and Buildings, 126 (2016), $275-286$. http://dx.doi.org/10.1016/j.enbuild.2016.05.021

ISO 13788:2012. Hygrothermal performance of building components and building elements - Internal surface temperature to avoid critical surface humidity and interstitial condensation - Calculation methods.

ISO 6946:2017. Building components and building elements - Thermal resistance and thermal transmittance - Calculation method.

ISO 9869-1:2014 Thermal insulation - Building elements - In-situ measurement of thermal resistance and thermal transmittance Heat flow meter method

Mumovic D., Ridley I., Oreszczyn T., Davies M. Condensation risk: comparison of steady-state and transient methods. Building Serv. Eng. Res. Technol. 27,3 (2006) pp. 219-233. https://doi.org/10.1191/0143624406bse163oa

Mao G. Thermal Bridges. Efficient Models for Energy Analysis in Buildings. Department of Building Sciences, Kunglika Tekniska Högskolan, Stockholm (1997).

Martin K., Erkoreka A., Flores I., Odriozola M., Sala J.M. Problems in the calculation of thermal bridges in dynamic conditions. Energy and Buildings, 43, (2011), 529-535. https://doi.org/10.1016/j.enbuild.2010.10.018

Theodosiou T.G, Papadopoulos A.M. The impact of thermal bridges on the energy demand of buildings with double brick wall constructions. Energy and Buildings, $\quad 40 \quad$ (2008), 2083-2089. https://doi.org/10.1016/j.enbuild.2008.06.006

$2030 \quad$ Energy Strategy. Energy https://ec.europa.eu/energy/en/topics/energystrategy-and-energy-union/2030-energy-strategy. [last access 30/01/2019]. 